\title{
Approaches to Learning in Statistics
}

\author{
Ayse Bilgin \\ Division of Economic and Financial Studies, Macquarie University \\ Sydney NSW 2109, Australia \\ Tel: 61-2-9850-8509 E-mail: abilgin@efs.mq.edu.au \\ Sue Crowe
}

Division of Economic and Financial Studies, Macquarie University

Sydney NSW 2109, Australia

Tel: 61-2-9850-8560Ｅ-mail: scrowe@efs.mq.edu.au

The research is financed by a Learning Excellence and Development (LEAD) grant from the Division of Economics and Financial Studies, Macquarie University, Australia.

\begin{abstract}
In the last decade, Australian higher education institutions have become a destination for many international students, mainly from South East Asia. If their educational culture is quite different to the Australian educational culture, then their approaches to learning might be different to that of local students. The aim of this pilot study was to investigate the approaches to learning of students in statistics units and relate these to background variables such as country of origin, gender and work commitments. This study is significant because there are many international students at Macquarie University and no data of this type has been collected for our students in the past.

Our analyses showed that there were no significant differences in the approaches to learning of local and international; and male and female students; however, we found a significant difference between undergraduate and postgraduate students, with postgraduates more likely to adopt deep strategies to learning.
\end{abstract}

Keywords: Learning approaches, Learning strategies, Learning motives, Statistics education; Internationalisation

\section{Introduction}

Statistical thinking is becoming almost a generic skill which could be used by many professionals such as accountants, marketing managers and medical practitioners. In many universities statistics courses are studied as service courses by students majoring in a range of other disciplines. Moreover, the study of statistics provides ideas and methods that could be utilised by students in order to better understand their environment at university and beyond (Garfield \& Ben-Zvi, in press). Utts (2003) emphasized that educated citizens should understand basic statistical concepts so that they can detect any misuse of statistics by policy makers, physicians and others.

With the increased amount of data collection due to the improvement in computers, the importance of quantitative skills is increasing. Unfortunately, Australia is facing a skill shortage in mathematics and statistics graduates who could be doing these analyses (Australian Academy of Science, 2006). One reason for these shortages might be statistics being considered a difficult subject by students.

For both statistically literate citizens and statistical professionals, it is important that they use a deep approach to their learning which will stay with them for life. Hubbard (1997), based on the research of Gal and Ginsburg (1994), and with no quantitative data, states that for many students statistics is, "merely a hurdle to be overcome on the way to obtaining a degree". If so, could the students be using a surface approach to their learning?

While Scheaffer (2001) suggests that it is important to utilise correct educational strategies that encourage deep learning approaches, such as active learning and problem-based learning by using authentic data in tutorials and emphasising the statistical thinking, the results of Gordon's study (1995) indicate and emphasise the impact of the students' personal experiences, motivation, perceptions, expectations, achievement goals, and the 'sociohistorical' context on their approaches to learning. Gordon calls for research into student learning approaches in statistics, rather than solely into the methods used to teach statistics.

With over 4600 international students studying "onshore" at Macquarie and approximately 120 studying "offshore", the Division of Economic and Financial Studies accounts for approximately 60\% of Macquarie University's international "onshore" students and 20\% of its "offshore" students (DEFS, 2006). The Department of Statistics offers courses to all 
students in the Division, therefore it is important to identify the learning approaches of students coming from other cultures compared to local students so that academics can help students to maximise their learning experiences and outcomes through making deep learning the only alternative.

Cross-cultural studies of general learning approaches of students have been investigated by a number of researchers to identify any possible differences between Australian and Asian - mainly South East Asian - students in a number of different disciplines, including accounting and engineering (Biggs \& Watkins, 2001; Kember \& Gow, 1990; Ramburuth, 2001; Volet \& Renshaw, 2001; Ginns, Prosser \& Barrie 2007; Gow et al., 1994; Kember, 2000; Smith \& Smith, 1999; Smith, 2001; Cooper, 2004; Biggs, 1991). We were not able, however, to find any cross-cultural research into the learning approaches of statistics' students in the literature.

The research, both within and without statistics education (Gordon, 1995; Gow et al., 1994; Kember, 2000; Ramburuth \& McCormick, 2001), has shown that there is a range of variables affecting students' approaches to learning. These variables include teaching approaches, learning theories, assessment methods and students' prior learning experiences and perceptions. Our study is a pilot study, designed to explore students' approaches to learning statistics from the students' perspective by utilising Bigg's Study Process Questionnaire (SPQ) (1987a).

\section{Literature review/Background}

It is evident from the extant literature that there is only limited research into students' approaches to learning in statistics. A number of studies investigate teaching approaches and learning theories in statistics education (Garfield, 1995; Keeler \& Steinhorst, 1995 \& 2001; Hubbard, 1997). Garfield (1995), on the basis of previous research (educational and psychological), highlights the importance of teaching approaches and learning theories in statistics education and how academics can support students' learning. In particular, the author argues for the implementation of activity-based courses, widespread use of cooperative learning groups, and the pedagogical theory of constructivism. This is further reinforced by Keeler and Steinhorst (1995), whose study of a cooperatively structured statistics course illustrates the impact of teaching and learning approaches imposed by the teacher. The authors' reported results indicate that not only did a larger percentage of students successfully complete the course, but those who did received higher grades compared with an earlier traditional offering of the course. The authors' later study (2001) examined an introductory statistics course, which was activity-based, cooperatively structured and located within a constructivist framework. The learning approaches of the students in this study are given in a very generalist manner, with the authors' approach reflecting a, "continuing belief that students learn better and retain more if they engage in learning activities that require them to think and process information rather than to passively listen to lectures". It is not reported in either study, however, how a cooperative learning approach or an enquiry-based approach (teaching approaches) impacted on the students' own approach to learning in statistics and whether it promoted a deep approach to learning in statistics.

There are many research articles comparing the learning approaches of Asian and Australian students in other disciplines, but few in statistics. One such research article is published by Cooper (2004) and concerns a comparative longitudinal study (using SPQ) of Australian and Malaysian Chinese students at RMIT University. It identified differences in the learning approaches of the two groups studied, for instance it was observed that Chinese male students consistently scored higher on the deep scores, despite outscoring Australian students on the surface approach scores. Cooper argues that the consistently good academic results of the Chinese students adopting surface approaches to learning do not support the hypothesis of a negative correlation between surface approaches and academic performance. The author suggests that, from a cultural perspective, memorisation should not be treated as rote learning, as the, "process of memorisation contributes to understanding and can be distinguished from mechanical memorisation" (p.294). The relatively small sample of Chinese students in the authors' study demonstrated that they could perform academically, whether adopting surface or deep approaches to learning.

Kember (2000), in addressing the common misperception of the 'Asian rote learner', observed that students often move between surface and deep approaches depending upon the nature of the assessment task and/or course requirements. Kember's observations are based on the results of a survey (Kember \& Gow, 1991) of 4,863 students from Hong Kong and Australia, in which data was collected using Bigg's SPQ. Kember also observed that the approach students adopt will be affected by curriculum design, assessment requirements, workload, teaching approach, and the students' perceptions of relevance and interest in the course. Furthermore, results from previous research indicate that curricula designed according to different pedagogies have markedly different impacts on the learning approaches of students. Gijbels and Dochy (2006) showed that there was a relationship between students' approaches to learning and their assessment preferences, where students who used a deep approach to learning preferred higher-order thinking assessment tasks and non-conventional assessment. On the other hand, Leung et al. (2006) showed that construction engineering students in mainland China were using more deep approaches than their counterparts in Hong Kong, even though the mainland Chinese students might lack resources and new teaching methods (such as action learning) that were available to students in Hong Kong.

Green (2007) showed that the appearance of a surface approach to essay writing by Asian students might be related to their lack of understanding the norms of Australian essay writing or, in other words, it is because of the cultural 
differences between the educational systems. She concludes her article by suggesting that to eliminate possible misunderstandings or clarify the academic expectations, students from Asian cultures need to be offered academic skills before or during their studies in Australia.

Other researchers have found no differences in approaches to learning between different cultural groups. For example, Smith (2005) was not able to identify any differences between the learning approaches of a culturally mixed group of students in the United Arab Emirates. This research showed that the students used very mixed approaches to their learning, which may be due to a very multicultural learning environment or the use of the revised SPQ - R-SPQ-2F (Biggs, Kember \& Leung, 2001).

The research into students' approaches to learning in different disciplines shows that there might be differences between local and international students. Some research also suggests that there may be differences between undergraduate and postgraduate students (Ling et al., 2005) as well as between male and female students (Elias, 2005). However, there is a big gap in the literature regarding the research into statistics students' approaches to learning. Although our study is a pilot study, it is designed to bring light into this area and suggest further research questions.

\section{Method}

We used Bigg's Study Process Questionnaire (SPQ) (1987a, 1987b) to identify learning approaches of statistics students along with an in-house developed demographic survey. The SPQ is a self-reporting survey consisting of 42 items on six subscales. There are seven items on each subscale. The six subscales are surface strategy (SS), surface motive (SM), deep strategy (DS), deep motive (DM), achieving strategy (AS) and achieving motive (AM). Three different learning approaches of students are calculated by summing up the strategy and motive of a certain approach, for example Surface Approach score is calculated by adding up surface strategy and surface motive scores (Table 1). Each item on the SPQ has a five-point scale ranging from (1) "this item is never or only rarely true of me" to (5) "this item is always or almost always true of me".

Table 1. Motive and Strategy in approaches to learning and studying (Biggs, 1987a, p.3)

\begin{tabular}{|l|l|l|}
\hline Learning Approach & Learning Motive & \multicolumn{1}{|c|}{ Learning Strategy } \\
\hline Surface Approach & $\begin{array}{l}\text { Surface motive (SM) is to meet } \\
\text { requirements minimally; a } \\
\text { balancing act between failing and } \\
\text { working no more than it is } \\
\text { necessary. }\end{array}$ & $\begin{array}{l}\text { Surface strategy (SS) is to limit } \\
\text { target to bare essentials and } \\
\text { reproduce them through rote } \\
\text { learning. }\end{array}$ \\
\hline Deep Approach & $\begin{array}{l}\text { Deep motive (DM) is intrinsic } \\
\text { interest in what is being learned: } \\
\text { to develop competence in } \\
\text { particular academic subjects. }\end{array}$ & $\begin{array}{l}\text { Deep strategy (DS) is to } \\
\text { discover meaning by reading } \\
\text { widely, inter-relating with } \\
\text { previous relevant knowledge. }\end{array}$ \\
\hline $\begin{array}{l}\text { Achieving Approach } \\
\text { (AA) }\end{array}$ & $\begin{array}{l}\text { Achieving motive (AM) is to } \\
\text { enhance ego and self-esteem } \\
\text { through competition; to obtain } \\
\text { highest grades, whether or not } \\
\text { material is interesting. }\end{array}$ & $\begin{array}{l}\text { Achieving strategy (AS) is to } \\
\text { organise one's time and working } \\
\text { space; to follow up all suggested } \\
\text { readings, schedule time, behave } \\
\text { as "model student". }\end{array}$ \\
\hline
\end{tabular}

The SPQ and demographic survey were administered before the mid-semester break in May 2007 in two separate classes, one second year undergraduate class and one postgraduate class. To eliminate any bias due to the lecturer being in the class during an anonymous survey, a research assistant (RA) was employed to oversee the process. After a short introduction by the lecturer about the study and inviting students to participate, the lecturer left the classroom and the RA administered the surveys. There were 65 students enrolled in the second year statistics course, Applied Statistics, where 39 of them participated in the study; while all 13 postgraduate students enrolled in the postgraduate Data Mining unit participated in the study. Even though the sample size is only 52, all students present at the lecture in each unit participated in the survey.

\section{Results}

The sample was reasonably evenly divided between male (43\%) and female (57\%) respondents. This split was significantly different in the two units, with $67 \%$ of the undergraduate unit being female and $25 \%$ of the postgraduate unit being female $\left(\chi^{2}=6.5, p=0.011\right)$. The average age of students in this study was approximately 23 years, with females having a slightly lower average age and males having a slightly higher average age. Most students were aged under 27, apart from two males in the postgraduate unit who were 31 and 46 . Not surprisingly, the average age in the 
postgraduate unit was higher than that in the undergraduate unit (27 years compared with 22). The proportion of students who were part time was significantly higher in the postgraduate unit $\left(50 \%\right.$ compared with $8 \%, \chi^{2}=11.3, p=$ 0.001). In addition, the postgraduate students reported working longer hours in employment than the undergraduate students.

The sample was split fairly evenly between students who identified themselves as an international student (53\%) and those who did not (47\%). The proportion of international students was not significantly different in the undergraduate and postgraduate units $\left(\chi^{2}=1.19, \mathrm{p}=0.276\right)$.

\subsection{The differences between undergraduate and postgraduate students}

The data suggested that the students in both postgraduate and undergraduate units showed a mix of learning approaches, with those having high surface approach scores varying from low to high deep scores. The comparative boxplot in Figure 1 shows the distribution of Motive and Strategy scores in the two units for the three dimensions of the SPQ. The undergraduate and postgraduate units do not show any large differences on either of the surface or achieving motive and strategy scores. It can be seen in Figure 1 that the students in the postgraduate unit do appear to have a higher median score on Deep Motive and Strategy scores than those in the undergraduate unit. Two sample t-tests were also used to test for differences in average scores between the undergraduate and postgraduate units on all of the motive and strategy scores. Only the comparison of the Deep Strategy score in the two groups was significant $(p=0.002)$. It is interesting to note that there is more variability in the Achieving Motive and Strategy scores in both groups, compared with both surface and deep scores

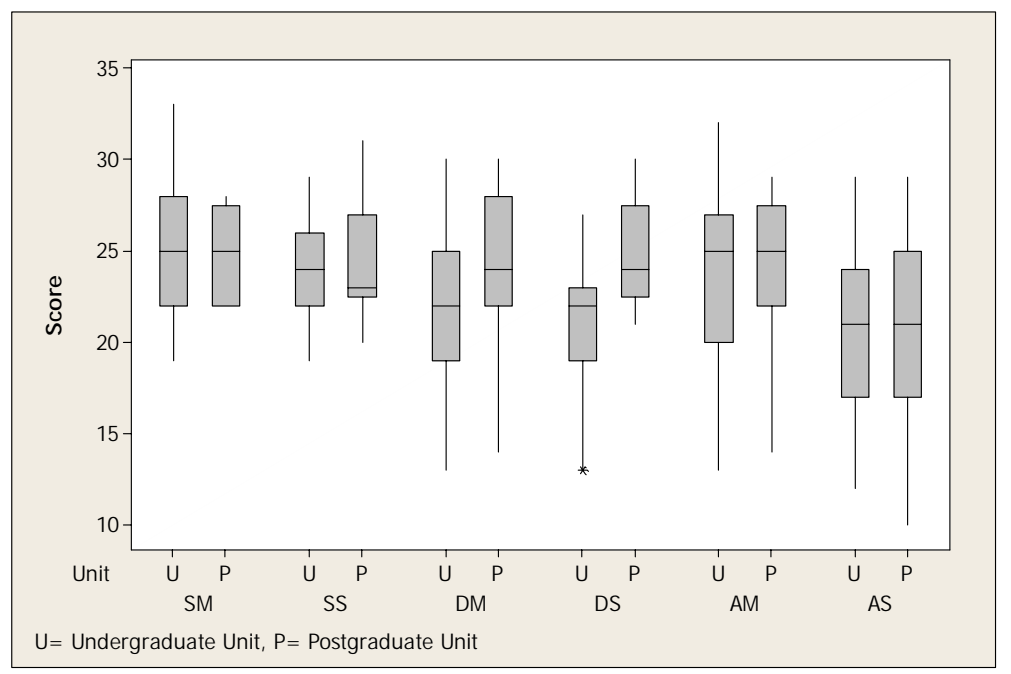

Figure 1. Distribution of Motive and Strategy scores by unit

The distribution of the Approach scores is shown in a comparative boxplot (Figure 2), and a similar pattern is seen there, that is, that the largest difference in the medians between the undergraduate and postgraduate students was on the Deep Approach scores. This comparison was the only significant one $(p=0.011)$.

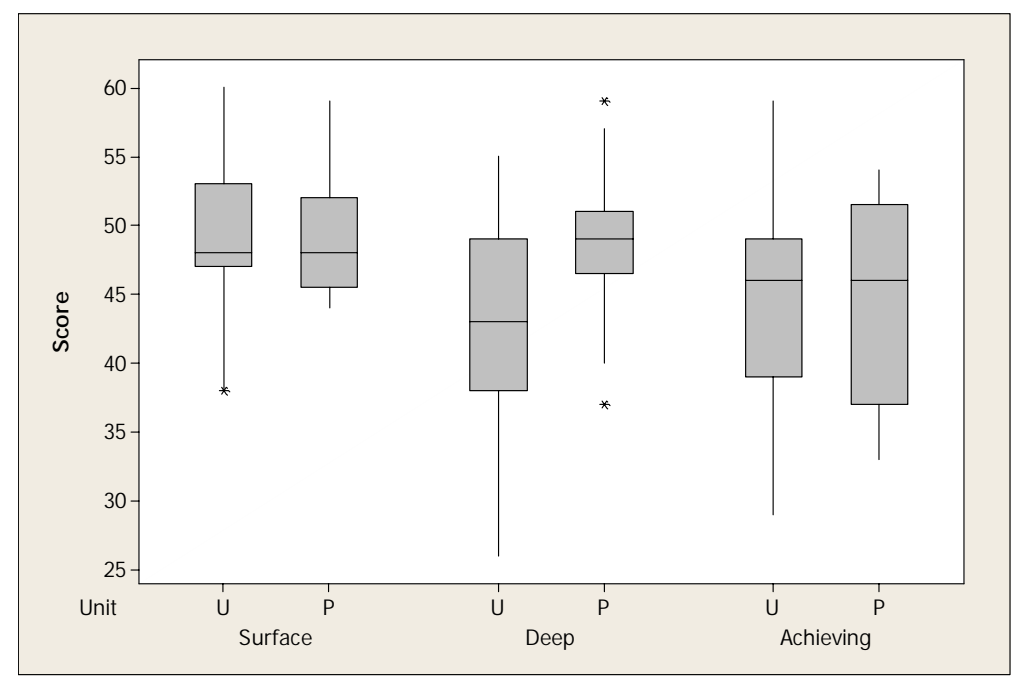

Figure 2. Distribution of Approach scores by unit 
While the postgraduate students were spending longer in employment each week, there did not appear to be any relation between scores on each of the scales and the number of hours of employment.

\subsection{The differences between international and Australian students}

A comparison was made of Motive and Strategy scores, and Approach scores, for students who stated that they were international students compared with those who said they were not. No large differences were seen between the two groups. The largest difference was in Deep Motive scores, but this was not significant $(p=0.055)$. Once again the variability in Surface scores was lower than either the Achieving or Deep scores.

\subsection{The differences between male and female students}

No significant differences in Motive, Strategy and Approach scores were found between male and female students. Once again, the variability in the Surface Motive and Strategy scores is lower than in the other scales.

\subsection{Relationship between the types of Motives, Strategies and Approaches}

The relationships between the strategy, motive and approach scores for each of the three types were either positive or non-significant. That is, there was no evidence that students who had high scores on one strategy, motive or approach tended to have lower scores on another strategy, motive or approach. There was some evidence that students aligned their motives and strategies, as there was a significant positive relationship between these scores for both Surface and Deep scores, with a stronger correlation for the Deep scores. That is, students with a high score on Surface Motive were likely to have a high score on Surface Strategy, and similarly for the Deep Motive and Deep Strategy scores. This trend was not evident for the Achieving scores.

\section{Implications for learning and teaching}

It is now possible to provide information regarding our statistics' students learning approaches. Our findings are in line with other researchers who have compared the learning approaches of Australian and Asian students: there is no significant difference between their approaches to learning. Anecdotal evidence can be put aside since both groups of students had a mixed approach to their learning.

As our results suggest that the students within a unit have similar approaches to their learning, our next step will be to examine our teaching and assessment strategies to identify possible impacts on student learning approaches. Conducting the SPQ before and after particular assessment tasks may be one possible way of exploring the impact of the learning and teaching environment.

\section{Conclusion}

This article presents results of a pilot study aimed to identify statistics students' learning approaches in an Australian university. The only significant difference we observed in our sample was the difference between the Deep Strategy scores of undergraduate versus postgraduate students. Our findings are similar to Ling et al.'s (2005) results, where they found no significant difference between the learning approaches of Australian and Malaysian students. They also found a significant difference between Australian undergraduate and postgraduate students, where postgraduate students used more deep approaches and undergraduate students used more surface approaches to their learning.

A deep learning approach is generally considered to be the most effective since it creates opportunities for learning that lasts. Our students mainly used a mixed approach to their learning, regardless of their gender or origin (local or international). Further research is needed to identify the underlying differences between undergraduate and postgraduate students' approaches to learning, since both of the units that were subject to this research had similar assessment strategies and teaching methods - we are currently unable to state why there was a significant difference between the two groups. One possible explanation may be that postgraduate students often have an authentic work-related problem which immediately highlights the importance of a deep understanding of statistics. In addition, deep strategy and motive scores of students could be improved by a better understanding of why the students chose to use a mixed approach to their learning. However, that issue was not part of this pilot study.

\section{Acknowledgements}

The authors wish to thank Brendan Rigby for his assistance with the literature review of this article.

\section{References}

Australian Academy of Science (2006). Mathematics and statistics: Critical skills for Australia's future. [Online] Available: http://www.review.ms.unimelb.edu.au/Report.html (June 16, 2006).

Biggs, J., Kember, D., \& Leung, D.Y.P. (2001). The revised two-factor Study Process Questionnaire: R-SPQ-2F. British Journal of Educational Psychology, 71, 133-149.

Biggs, J., \& Watkins, D.A. (2001). Teaching the Chinese learner: Psychological and pedagogical perspectives. Hong Kong: Hong Kong University Press. 
Biggs, J. (1991). Approaches to learning in secondary and tertiary students in Hong Kong: Some comparative studies. Educational Research Journal, 6, 27-39.

Biggs, J. (1991). Good learning: What is it? How can it be fostered? In J. Biggs (Ed.), Teaching for learning: The view from cognitive psychology (pp. 215-230). Hawthorn, Victoria: Australian Council for Educational Research,.

Biggs, J. B. (1987a). Study Process Questionnaire manual. Melbourne: Australian Council for Educational Research.

Biggs, J. B. (1987b). Student approaches to learning and studying. Melbourne: Australian Council for Educational Research.

Cooper, B. J. (2004). The enigma of the Chinese learner. Accounting Education, 13 (3), 289-310.

Division of Economic and Financial Studies (DEFS) (2006). 2005 Annual Report to Academic Senate. Sydney: Macquarie University. [Online] Available: http://senate.mq.edu.au/documents/EFSReportSenate_0206.doc (September 21, 2007).

Elias, R. Z. (2005). Students' approaches to study in introductory accounting courses. Journal of Education for Business. March/April, 194-199.

Gal, I., \& Ginsburg, L. (1994). The role of beliefs and attitudes in learning statistics: Towards an assessment framework. Journal of Statistics Education, 2 (2), 1-15.

Garfield, J. (1995). How students learn statistics. International Statistical Review, 63 (1), 25-34.

Garfield, J. B. \& Ben-Zvi, D. (in press). Developing students' statistical reasoning: Connecting research and teaching practice. Emeryville, CA: Key College Publishing.

Gijbels, D., \& Dochy, F. (2006). Students' assessment preferences and approaches to learning: Can formative assessment make a difference? Educational Studies, 32 (4), 399-409.

Ginns, P., Prosser, M., \& Barrie, S. (2007). Students' perceptions of teaching quality in higher education: The perspectives of currently enrolled students. Studies in Higher Education, 32 (5), 603-615.

Gordon, S. (1995). A theoretical approach to understanding learners of statistics. Journal of Statistical Education, 3 (3), $1-16$.

Gow, L., Kember, D., \& Cooper, B. (1994). The teaching context and approaches to study of accountancy students. Issues in Accounting Education, 9 (1), 118-30.

Green, W. (2007). Write on or write off? An exploration of Asian international students' approaches to essay writing at an Australian University. Higher Education Research \& Development, 26 (3), 329-344.

Hubbard, R. (1997). Assessment and the process of learning statistics. Journal of Statistics Education, 5 (1), 1-8.

Keeler, C., \& Steinhorst, K. (1995). Using small groups to promote active learning in the introductory statistics course: A report from the field. Journal of Statistics Education, 3 (2), 1-8.

Keeler, C., \& Steinhorst, K. (2001). A new approach to learning probability in the first statistics course. Journal of Statistics Education, 9 (3), 1-24.

Kember, D., \& Gow, L. (1990). Cultural specificity of approaches to study. British Journal of Educational Psychology, 60, 356-363.

Kember, D., \& Gow., L. (1991). A challenge to the anecdotal stereotype of the Asian student. Studies in Higher Education, 16 (2), 117-128.

Kember, D. (2000). Misconceptions about the learning approaches, motivation and study practices of Asian students. Higher Education, 40, 99-121.

Leung, M. Y., Li, J., Fang, Z., Lu, X., \& Lu, M. (2006). Learning approaches of construction engineering students: A comparative study between Hong Kong and mainland China. Journal for Education in the Built Environment, 1 (1), 112-131.

Ling, P., Arger, G., Filonenko, I., Chua, H., \& Yin, C. (2005). Approaches to study: A comparison of Malaysian and Australian students. Proceedings of Xth HERDSA Conference (pp. 276-286).

Ramburuth, P. (2001). Cross cultural learning behaviour in higher education: Perceptions and practice. Ultibase publication. [Online] Available: http://ultibase.rmit.edu.au/Articles/may01/ramburuth1.htm (May 15, 2006).

Ramburuth, P., \& McCormick, J. (2001). Learning diversity in higher education: A comparative study of Asian international and Australian students. Higher Education, 42, 333-50.

Scheaffer, R. L. (2001). Statistics education: Perusing the past, embracing the present, and charting the future. Newsletter for the Section on Statistical Education, 7,(1), (Winter). 
Smith, L. (2005). An investigation into student approaches to learning at a multicultural university using the Revised Study Process Questionnaire. Proceedings of Xth HERDSA Conference (pp. 533-541).

Smith, P. J., \& Smith, S. N. (1999). Differences between Chinese and Australian students: Some implications for distance educators. Distance Education, 20 (1), 64-80.

Utts, J. (2003). What educated citizens should know about statistics and probability. The American Statistician, 57 (2), 74-79.

Volet, S., \& Renshaw, P. (1996) Chinese students at an Australian university: Adaptability and continuity. In D. A. Watkins, \& J. B. Biggs (Eds.) The Chinese learner: Cultural, psychological and contextual influences (pp.205-220). Hong Kong: Comparative Education Research Centre; and Melbourne, Victoria: Australian Council for Educational Research. 